\title{
A INFLUÊNCIA DOS ORGANISMOS MULTILATERAIS INTERNACIONAIS NA FORMAÇÃO DAS POLÍTICAS BRASILEIRAS DE ALFABETIZAÇÃO
}

\author{
OLIVEIRA, Lidiane Malheiros Mariano* \\ GUIMARÃES, Lucélia Tavares **
}

\begin{abstract}
RESUMO
As políticas públicas de educação têm sido elaboradas de modo a atender as exigências constantes nos documentos propostos por organismos multilaterais internacionais, cujos resultados indicam conquistas de alguns avanços e desafios que ainda precisam ser superados. Este artigo tem como propósito estabelecer reflexão sobre as políticas públicas de alfabetização para a educação básica no Brasil. Apresenta como objetivo compreender quais são, na atualidade, as influências da regulação transnacional dos organismos multilaterais nas políticas de alfabetização em nível nacional. Foi realizada uma análise crítica desses documentos para compreender como o tema 'alfabetização' aparece nos documentos oficiais desses órgãos, quais sejam: UNESCO, UNICEF e Banco Mundial. O estudo abordou as perspectivas legais de acordo com o 'Plano de Meta Compromisso Todos pela Educação', o 'Plano de Desenvolvimento da Educação' (PDE) e o 'Plano Nacional de Educação' (PNE/2014), que sustentam a criação dessas políticas. A partir dos estudos de documentos elaborados após a conferência mundial de "Educação para todos", em 1990, foi possível verificar muita similaridade entre os aspectos priorizados nas recomendações de organismos multilaterais e as políticas implantadas no Brasil.
\end{abstract}

Palavras- chave: Políticas Públicas. Alfabetização. Organismos Multilaterais

\footnotetext{
* Professora da Rede Municipal de Ensino de Paranaíba-MS; Licenciada em Pedagogia e Especialista pela FIPAR (Faculdades Integradas de Paranaíba); Mestre em Educação pela Universidade Estadual de Mato Grosso do Sul (UEMS), Unidade de Paranaíba/MS; Doutoranda do Programa de Pós Graduação em Educação Escolar da Universidade Estadual Paulista "Júlio de Mesquita Filho" (UNESP), campus de Araraquara. E-mail: lidiane_nane@yahoo.com.br

** Doutora em Educação: Currículo pela Pontifícia Universidade Católica de São Paulo (PUCSP). Coordenadora do curso de Pedagogia da Universidade Estadual de Mato Grosso do Sul (UEMS). Professora Titular da Universidade Estadual de Mato Grosso do Sul (UEMS), Unidade Universitária de Paranaíba/MS, nos cursos de graduação em Pedagogia e Ciências Sociais. E-mail: luguimaraes@uems.br
}

Lidiane Malheiros Mariano OLIVEIRA,Lucélia Tavares Guimarães A influência dos organismos multilaterais internacionais na formação das políticas brasileiras de alfabetização. 


\title{
$e$-Curriculum
}

Programa de Pós-Graduação em Educação: Currículo

\section{THE INFLUENCE OF INTERNATIONAL MULTILATERAL ORGANIZATIONS IN THE FORMATION OF BRAZILIAN LITERACY POLICIES}

\author{
OLIVEIRA, Lidiane Malheiros Mariano* \\ GUIMARÃES, Lucélia Tavares ${ }^{* * *}$
}

\begin{abstract}
Public education policies have been developed in order to meet the requirements set out in the documents proposed by international multilateral organizations, whose results indicate the achievement of some advances and challenges that still need to be overcome. This article aims to establish reflection on the public literacy policies for basic education in Brazil. It presents as an objective to understand what are, at present, the influences of the transnational regulation of the multilateral organisms in the literacy policies at national level. A critical analysis of these documents was carried out to understand how the topic 'literacy' appears in the official documents of these bodies, namely: UNESCO, UNICEF and the World Bank. The study addressed the legal perspectives in line with the 'All Commitment to Education Plan', the 'Education Development Plan' (PDE) and the 'National Education Plan' (PNE / 2014) that support the creation of these Policies. Based on document studies developed after the World Conference on Education for All in 1990, it was possible to verify a great similarity between the aspects prioritized in the recommendations of multilateral organizations and the policies implemented in Brazil.
\end{abstract}

Keywords: Public Policies. Literacy. Multilateral Organizations

\footnotetext{
* Teacher in the Municipal Education System in Paranaíba, Mato Grosso do Sul State; Graduated in Pedagogy and Post Graduated at FIPAR - Faculdades Integradas de Paranaíba (Integrated Colleges in Paranaíba); Master's Degree at UEMS - Universidade Estadual de Mato Grosso do Sul (State University of Mato Grosso do Sul); Doctorate Student in the Postgraduate Program in Education at UNESP - Universidade Estadual Paulista "Júlio de Mesquita Filho" (São Paulo State University “Julio de Mesquita Filho”), Araraquara Campus in São Paulo state. Email: lidiane_nane@yahoo.com.br

** Doctor's Degree in Education: Curriculum at PUCSP - Pontifícia Universidade Católica de São Paulo (Pontifical Catholic University of São Paulo); Pedagogy Course Coordinator at UEMS - Universidade Estadual de Mato Grosso do Sul (State University of Mato Grosso do Sul); Full Professor at UEMS - Universidade Estadual de Mato Grosso do Sul (State University of Mato Grosso do Sul) in the Pedagogy and Social Science Course in Paranaíba, Mato Grosso do Sul State. E-mail: luguimaraes@uems.br
}

$=======$

Revista e-Curriculum, São Paulo, v.15, n.3, p. 842 - 870 jul./set.2017

e-ISSN: 1809-3876

Programa de Pós-graduação Educação: Currículo - PUC/SP

http://revistas.pucsp.br/index.php/curriculum 


\title{
$e$-Curriculum
}

Programa de Pós-Graduação em Educação: Currículo

\section{LA INFLUENCIA DE LOS ORGANISMOS INTERNACIONALES EN LA FORMACIÓN DE POLÍTICAS BRASILEÑAS DE ALFABETIZACIÓN}

\author{
OLIVEIRA, Lidiane Malheiros Mariano * \\ GUIMARÃES, Lucélia Tavares **
}

\begin{abstract}
RESUMEN
Las políticas públicas de educación han sido elaboradas de forma que atiendan las exigencias constantes en los documentos propuestos por organismos multilaterales internacionales, cuyos resultados indican logros de algunos avanzos y retos que todavía necesitan ser superados. Ese artículo tiene como finalidad establecer reflexiones sobre las políticas públicas de alfabetización para la educación básica en Brasil. Presenta como objetivo comprender cuales son las influencias actuales de la regulación transnacional de los organismos multilaterales en las políticas de alfabetización a nivel nacional. Un análisis crítico de los documentos oficiales de esos organismos fue llevado a cabo, agregando los siguientes organismos: UNESCO, UNICEF y Banco Mundial. El estudio abordó las perspectivas legales de acuerdo con el "Plan de Meta Compromiso Todos por la Educación", el "Plan de Desarrollo de la Educación" (PDE) y el " Plan Nacional de Educación" (PNE/2014), que sostienen la creación de esas políticas. A partir del estudio de los documentos elaborados después de la conferencia mundial de "Educación para todos", en 1990, se hizo posible averiguar mucha similitud entre los aspectos priorizados en las recomendaciones de organismos multilaterales y las políticas implantadas en Brasil.
\end{abstract}

Palabras-clave: Políticas Públicas. Alfabetización. Organismos Multilaterales.

\footnotetext{
* Profesora de la Red Municipal de Enseñanza de Paranaíba-MS; Licenciada en Pedagogía y Especialista por la FIPAR (Facultades Integradas de Paranaíba); Maestra en Educación por la Universidad Estadual de Mato Groso del Sur (UEMS), Unidad de Paranaíba/MS; Doctoranda del Programa de Postgrado en Educación Escolar de la Universidad Estadual Paulista “Julio de Mesquita Filho” (UNESP), campus de Araraquara. Correo electrónico: lidiane_nane@yahoo.com.br

**Doctora en Educación: Currículum por la Pontifica Universidad Católica de San Pablo (PUCSP). Coordinadora del curso de Pedagogía de la Universidad Estadual de Mato Groso del Sur (UEMS). Profesora Titular de la Universidad Estadual de Mato Groso del Sur (UEMS), Unidad Universitaria de Paranaíba/MS, en los cursos de grado en Pedagogía y ciencias sociales.Correo electrónico: luguimaraes@uems.br.
}

Lidiane Malheiros Mariano OLIVEIRA,Lucélia Tavares Guimarães A influência dos organismos multilaterais internacionais na formação das políticas brasileiras de alfabetização. 


\section{$e$-Curriculum}

Programa de Pós-Graduação em Educação: Currículo

\section{INTRODUÇÃO}

Este artigo é parte de uma dissertação intitulada "Pacto Nacional pela Alfabetização na Idade Certa (PNAIC): provocações e possíveis mudanças da formação continuada à prática do professor alfabetizador" e tem como objetivo compreender quais são, na atualidade, as influências da regulação transnacional dos organismos multilaterais nas políticas de alfabetização em nível nacional. Efetuamos, para tanto, uma análise crítica das múltiplas determinações dessas políticas.

Documentos internacionais de importantes organismos multilaterais atribuíram à educação a sustentação da competitividade nos anos 1990, a partir de "[...] diagnósticos, análises e propostas de soluções consideradas cabíveis a todos os países da América Latina e Caribe, tanto no que toca à educação quanto à economia" (SHIROMA; MORAIS; EVANGELISTA, 2011, p. 47).

Articuladas aos documentos propostos por organismos multilaterais internacionais, têm sido elaboradas e implementadas políticas públicas de educação e alfabetização cujos resultados indicam a conquista de alguns avanços e desafios que precisam ser superados.

O principal enfoque será dado a três organizações, a saber: o Fundo das Nações Unidas para a Infância (UNICEF); a Organização das Nações Unidas para a Educação, a Ciência e a Cultura (UNESCO) e o Banco Mundial, as quais foram escolhidas em virtude de seu posicionamento estratégico em relação às políticas voltadas à alfabetização.

Como explica Mortatti (2013), muitos desses documentos constituem a consensual meta da qualidade da educação e da alfabetização escolar de crianças, pois "Ao longo da segunda metade do século XX, o objetivo de combater o analfabetismo tornou a alfabetização um direito que 'precede', como pré-requisito, o direito à educação e aos demais direitos humanos" (MORTATTI, 2013, p. 30). O direcionamento dessas propostas sugere, portanto, que uma vez solucionados os problemas com a alfabetização no país, os outros transtornos, como educacionais, sociais e políticos também estariam resolvidos. 


\section{e-Curriculum}

Programa de Pós-Graduação em Educação: Currículo

No Brasil, sustentam a criação dessas políticas e, ainda, as atuais iniciativas do governo brasileiro neste setor, o Decreto $\mathrm{n}^{\circ}$ 6.094, de 24 de abril de 2007 (BRASIL, 2007), que determina a implementação do Plano de Meta Compromisso Todos pela Educação; o Plano de Desenvolvimento da Educação (PDE), lançado pelo Ministério de Educação (MEC) em 24 de abril de 2007; e a Lei no 13.005, de 25 de junho de 2014 (BRASIL, 2014a), que aprova o Plano Nacional de Educação - PNE, com vigência de dez anos após a data da publicação.

O exame desses documentos permite verificar muita similaridade entre os aspectos priorizados nas recomendações de organismos multilaterais e as políticas implantadas no Brasil com o objetivo de superar o analfabetismo.

\section{QUESTÕES E DILEMAS DAS FORMAÇÕES DE POLÍTICAS EDUCACIONAIS DE ALFABETIZAÇÃO}

De acordo com Mortatti (2013), ainda que a educação seja uma aspiração da sociedade letrada, especialmente a partir da Idade Moderna, é no campo das iniciativas mundiais dos meados do século XX que a educação é declarada como um direito humano a ser garantido a todos e um meio para promoção do respeito a todos os direitos e liberdades individuais. A alfabetização, nesse sentido, é declarada como uma "base" para a educação e para a aprendizagem ao longo da vida. De acordo com Cury (2002, p. 260),

O acesso à educação é também um meio de abertura que dá ao indivíduo uma chave de autoconstrução e de se reconhecer como capaz de opções. O direito à educação, nesta medida, é uma oportunidade de crescimento cidadão, um caminho de opções diferenciadas e uma chave de crescente estima de si (CURY, 2002, p. 260).

Embora as oportunidades de universalização da educação ainda não tenham se efetivado, “[...] a educação como direito e sua efetivação em práticas sociais se convertem em instrumento de redução das desigualdades e das discriminações e possibilitam uma aproximação pacífica entre os povos de todo o mundo" (CURY, 2002, p. 261).

Lidiane Malheiros Mariano OLIVEIRA,Lucélia Tavares Guimarães A influência dos organismos multilaterais internacionais na formação das políticas brasileiras de alfabetização. 


\section{$e$-Curriculum}

Programa de Pós-Graduação em Educação: Currículo

Cury (2002) explica que o fato de os organismos internacionais passarem a fazer desses

direitos um motivo de declarações e de convenções revela uma tendência de internacionalização.

Quando são reconhecidos novos direitos, as especificações acontecem e surgem, assim, novos modelos que atendem às peculiaridades educacionais.

Para Afonso (2001, p. 24),

[...] é inegável que, com uma intensidade maior ou menor, todos os países se confrontam hoje com a emergência de novas organizações e instâncias de regulação supranacional (ONGs, Mercosul, Organização Mundial do Comércio, União Europeia), cuja influência se vem juntar a outras organizações que já não são recentes, mas que continuam a ser muito influentes (Banco Mundial, OCDE, FMI), sendo que elas têm sempre implicações diversas, entre as quais, e de acordo com o objecto deste trabalho, aquelas que directa ou indirectamente ditam os parâmetros para a reforma do Estado nas suas funções de aparelho político-administrativo e de controle social, ou que induzem em muitos e diferentes países a adopção de medidas ditas modernizadoras que levam o Estado a assumir também, de forma mais explícita, uma função de mediação, de adequação às prioridades externamente definidas ou, mesmo, de promoção das agendas que se circunscrevem a ditames mais ou menos ortodoxos da fase actual de transnacionalização do capitalismo e de globalização hegemónica (AFONSO, 2001, p. 24).

Assim, as políticas criadas em todos os países acabam sendo influenciadas pelas metas propostas por esses organismos multilaterais que, de uma forma ou de outra, acabam por contribuir para o capitalismo e defender as necessidades de domínios de competências básicas para atender à demanda do mercado de trabalho.

Em 1990, aconteceu a Conferência Mundial de Educação para Todos, financiada pela Organização das Nações Unidas para a Educação, a Ciência e a Cultura - UNESCO, pelo Fundo das Nações Unidas para a Infância - UNICEF, pelo Programa das Nações Unidas para o Desenvolvimento - PNUD e pelo Banco Mundiali. Participaram desse evento agências internacionais, Organizações Não Governamentais (ONG), governos, associações, profissionais e personalidades de destaque no plano educacional em todo mundo. "Os 155 governos que subscreveram a declaração ali aprovada comprometeram-se a assegurar uma educação básica de qualidade a crianças, jovens e adultos" (SHIROMA; MORAIS; EVANGELISTA, 2011, p. 47). 


\section{e-Curriculum}

Programa de Pós-Graduação em Educaçãa: Currículo

Foram definidas estratégias e metas, relativas à educação básica, para serem executadas durante a década seguinte, a partir de um consenso político e ideológico que resultou em um projeto educacional internacional, com novas definições e abordagens sobre as necessidades básicas de aprendizagens. Cada país estabeleceu suas metas para a década, em consonância com as dimensões propostas pela Declaração Mundial sobre Educação para Todos.

1. Expansão dos cuidados básicos e atividades de desenvolvimento infantil, incluídas aí as intervenções da família e da comunidade, direcionadas especialmente às crianças pobres, desassistidas e portadoras de deficiências;

2. Acesso universal e conclusão da educação fundamental (ou qualquer nível mais elevado de educação considerado "básico") até o ano 2000;

3. Melhoria dos resultados de aprendizagem, de modo que a percentagem convencionada de uma amostra de idade determinada (por exemplo, 80\% da faixa etária de 14 anos), alcance ou ultrapasse o padrão desejável de aquisição de conhecimentos previamente definido;

4. Redução da taxa de analfabetismo adulto à metade, digamos, do nível registrado em 1990, já no ano 2000 (a faixa etária adequada deve ser determinada em cada país). Ênfase especial deve ser conferida à alfabetização da mulher, de modo a reduzir significativamente a desigualdade existente entre os índices de alfabetização dos homens e mulheres;

5. Ampliação dos serviços de educação básica e capacitação em outras habilidades essenciais necessárias aos jovens e adultos, avaliando a eficácia dos programas em função de mudanças de comportamento e impactos na saúde, emprego e produtividade;

6. Aumento da aquisição, por parte dos indivíduos e famílias, dos conhecimentos, habilidades e valores necessários a uma vida melhor e um desenvolvimento racional e constante, através de todos os canais da educação inclusive dos meios de comunicação de massa, outras formas de comunicação tradicionais e modernas, e ação social -, sendo a eficácia destas intervenções avaliadas em função das mudanças de comportamento observadas (UNICEF, 1990, n.p).

Segundo Shiroma, Moraes e Evangelista (2011), vários seminários aconteceram no Brasil após a conferência ocorrida em Jomtien, pois a expressão "para todos", constante na nomenclatura da proposta brasileira, recomendava uma universalização da educação básica desde a educação infantil ao ensino médio, porém não era esse o foco daquele evento internacional. Ademais, “[...] alguns autores compreenderam o conceito de Necessidades Básicas de Aprendizagens (NEBA) em sua função ideológica de indicar a natureza do ensino a ser ministrado. Isto é, para extratos sociais diferentes, ensinos diferentes, uma vez que as 


\section{e-Curriculum}

Programa de Pós-Graduação em Educação: Currículo

necessidades básicas de um e outro não poderiam ser as mesmas" (SHIROMA; MORAIS; EVANGELISTA, 2011, p. 52). Assim, as classes menos favorecidas continuariam a receber um atendimento educacional diferenciado e inferior ao das classes mais altas, pois ainda há naquele patamar social crianças fora da escola; as que têm acesso ao mundo escolar não concluem todos os ciclos; entre os concluintes, a maioria não domina o sistema de escrita alfabética; além de não terem o completo domínio das quatro operações matemáticas, apesar dos esforços empreendidos pelos órgãos oficiais brasileiros e por outros países, para assegurar o direito à educação para todos.

O lançamento do Plano Decenal de Educação para todos, em 1993, demonstra que o Brasil delineava intenções locais a partir do acordo firmado em Jomtien e que o projeto educacional pensado por organismos multilaterais estava sendo implantado no país.

Também nesse período, entre 1993 e 1996, foi produzido o "Relatório Delors", documento elaborado por uma Comissão Internacional sobre a Educação para o século XXI, criada pela UNESCO e coordenada pelo francês Jacques Delors. De acordo com Shiroma, Morais e Evangelista (2011, p. 55), esse "[...] é um documento fundamental para compreender a revisão da política educacional de vários países na atualidade". O relatório trata das tendências e necessidades que caracterizaram o final do século XX e destaca o papel que a educação deveria assumir. Com o conceito de educação ao longo da vida, a comissão defende:

[...] a ideia de educação permanente que deve ser, simultaneamente, reconsiderada e ampliada; com efeito, além das necessárias adaptações relacionadas com as mudanças da vida profissional, ela deve ser uma construção contínua da pessoa, de seu saber e de suas aptidões, assim como de sua capacidade para julgar e agir (DELORS et al., 1996, p. 12).

Com esse propósito, cada um deve utilizar de todas as formas para aprender e aperfeiçoar suas potencialidades, e de acordo com essa ideologia o desejável é “[...] que a escola venha a incrementar, cada vez mais, o gosto e prazer de aprender, a capacidade de aprender a aprender, além da curiosidade intelectual" (DELORS et al., 1996, p.12).

Esse conceito de educação seria adquirido a partir de quatro tipos de aprendizagens: 


\section{e-Curriculum}

[...] aprender a conhecer, isto é, adquirir os instrumentos da compreensão; aprender a fazer, para poder agir sobre o meio envolvente; aprender a viver junto, a fim de participar e cooperar com os outros em todas as atividades humanas; finalmente aprender a ser, via essencial que integra as três precedentes (DELORS et al., 2006, p.90)

De acordo com a comissão, o ensino deve considerar cada um dos quatro pilares, para que a educação apareça como uma experiência global ao longo de toda a vida para o indivíduo.

As autoras Shiroma, Morais e Evangelista (2011, p. 56-57) destacam: para sobreviver na sociedade da informação, é preciso que todos adquiram, atualizem e utilizem os conhecimentos, o que supõe a existência de uma educação básica capaz de construir a indispensável “[...] competência na leitura, escrita, expressão oral, cálculo, resolução de problemas e, no plano do comportamento, possibilitar o desenvolvimento de aptidões, valores e atitudes". Na perspectiva da comissão, a educação básica é a primeira etapa que os indivíduos devem ultrapassar para diminuir a grande disparidade que permeia os grupos humanos marginalizados, quais sejam: mulheres, populações rurais, minorias étnicas marginalizadas, crianças de baixa condição econômica, entre outros.

O professor é visto como peça fundamental para a realização dessas ideias. Dessa forma, o relatório recomenda que todos os governos deveriam empenhar esforços para reafirmar a importância desses profissionais da educação básica e criar condições para melhor qualificá-los.

Para Delors et al. (2006), a falta de financiamento e de meios pedagógicos, assim como a superlotação das turmas, traduziu-se, frequentemente, em uma profunda degradação das condições de trabalho dos professores, pois quando a escola passou a receber alunos com grandes dificuldades sociais e familiares, novas tarefas lhes foram impostas, embora muitos deles não estivessem preparados para exercê-las. "Quanto maiores forem as dificuldades que o aluno tiver que ultrapassar - pobreza, meio social difícil, doenças físicas - mais se exige do professor" (DELORS et al., 2006, p. 158-159). Ou seja, para o ensino ser eficaz, o professor deverá recorrer a diversas competências pedagógicas, com paciência e determinação.

Segundo Shiroma, Morais e Evangelista (2011), o Relatório Delors defende recomendações para o exercício da docência, de acordo com as demais agências e organismos multilaterais; prescreve orientações a vários níveis de ensino e evidencia uma concepção de 


\section{e-Curriculum}

Programa de Pós-Graduação em Educação: Currículo

educação que tem o papel de garantir a sobrevivência de valores consensuais na sociedade e incentivar o respeito às crenças culturais do ocidente.

O Banco Internacional para a Reconstrução e o Desenvolvimento (BIRD) é uma das instituições que integra o Banco Mundial - organismo internacional cujo maior desafio é a redução da pobreza no mundo. "Apesar de duas décadas de crescimento, a pobreza não diminui e os organismos internacionais, principalmente o Banco Mundial, se viram obrigados a ampliar o leque de setores nos quais deveriam investir" (AFONSO; GUBERMAN, 2007, p. 8).

De acordo com o Relatório $\mathrm{n}^{\circ}$ 63.731do Banco Mundial (2011), um rápido progresso social foi observado no Brasil, na área da educação, em 2011, que registrou $98 \%$ das crianças entre 7 e 14 anos matriculadas na escola. Segundo o mesmo órgão, "Melhorias complementares na quantidade e qualidade de capital humano são essenciais para aumentar a produtividade da mão de obra" (BANCO MUNDIAL, 2011, p. 10). Dessa forma, aponta que nos últimos 15 anos a expansão da escolaridade no Brasil teve efeitos dramáticos na força de trabalho, já que $70 \%$ não havia concluído o ensino médio em 1993 e, atualmente, esse número diminuiu para 40\%.

Em relação à educação básica, a maior mudança observada pela referida organização não é o acesso à escola fundamental, mas uma grande parcela de crianças que estão permanecendo na escola até o ensino médio: "[...] a implicação primordial é a urgência de se elevar os padrões de aprendizado dos alunos especialmente entre crianças pobres" (BANCO MUNDIAL, 2011, p. 10).

Segundo Piana (2009), a história da educação é marcada por sinais profundos da exclusão social, econômica e cultural. A autora afirma tratar-se de uma educação sem investimentos e oportunidades, sob o domínio de organismos nacionais e internacionais, que direcionam os rumos da educação brasileira para uma ação mercantilista e destinada a uma classe menos favorecida, pois "[...] milhares de crianças, adolescentes e jovens, mesmo matriculados em uma escola, permanecem excluídos de uma educação participativa, democrática, conscientizadora, dialógica, autônoma e afetiva" (PIANA, 2009, p. 57).

O programa do Banco Mundial compreende quatro objetivos estratégicos para atingir a meta, no Brasil, de crescimento mais rápido, mais inclusivo e ambientalmente sustentável, com estabilidade macroeconômica. 


\section{e-Curriculum}

Programa de Pós-Graduação em Educaçãa: Currículo

No tocante à educação, o segundo objetivo estratégico é "Melhorar a qualidade e expandir a prestação de serviços públicos para as famílias de baixa renda" (BANCO MUNDIAL, 2011, p. 22).

De acordo com o Relatório nº. 63.731do Banco Mundial (2011), o órgão pretende apoiar a educação do Brasil da seguinte maneira: continuar a ampliar o financiamento da Cooperação Financeira Internacional para instituições do setor privado de ensino pós-secundário, com foco em estudantes de baixa e média renda; formar parcerias com o Ministério de Educação para o fortalecimento das políticas de educação, sobretudo com vistas às funções normativas e de supervisão; apoiar a elaboração, implementação e avaliação de impacto de programas pilotos de educação direcionados a famílias de baixa renda em grandes municípios; criar parcerias com o MEC e governos selecionados por meio de Atividade de Análise e Parcerias - AAP e apoio ao combate aos principais problemas educacionais, com inclusão de abordagens para melhorar a condição do professor, diminuir as taxas de repetição, as distorções idade/ano e a qualidade do ensino médio. Sobre esse financiamento, Altmann (2002, p. 79) afirma que:

Embora a política de crédito do BIRD à educação se autodenomine cooperação ou assistência técnica, ela nada mais é do que um cofinanciamento cujo modelo de empréstimo é do tipo convencional, tendo em vista os pesados encargos que acarreta e também a rigidez das regras e as precondições financeiras e políticas inerentes ao processo de financiamento comercial (ALTMANN, 2002, p. 79).

Assim, os investimentos conferidos à educação são parte de um projeto econômico projetado por essas organizações. Nesse sentido, o Relatório n. ${ }^{\circ} 63.731$ (BANCO MUNDIAL, 2011) refere-se à necessidade de maior investimento na educação básica de maneira geral e não cita, especificamente, a alfabetização.

O Fundo das Nações Unidas para a Infância - UNICEF é uma agência mundial da Organização das Nações Unidas - ONU que se dedica nomeadamente às crianças. Na sede das Nações Unidas, em Nova York, em setembro de 2000, reuniram-se representantes de 189 paísesmembros das Nações Unidas, com o intuito de refletir sobre o destino comum da humanidade. A diferença social e econômica da realidade desses países era enorme, como se observa a seguir:

Lidiane Malheiros Mariano OLIVEIRA,Lucélia Tavares Guimarães A influência dos organismos multilaterais internacionais na formação das políticas brasileiras de alfabetização. 


\section{e-Curriculum}

Enquanto alguns países podiam esperar do futuro a prosperidade e a cooperação mundial, outros quase careciam de futuro, já que seus habitantes se encontravam atolados em condições miseráveis, intermináveis, de pobreza, de conflitos e em meio a um ambiente cada vez mais degradado (UNICEF, 2014, p. 8).

As atividades desenvolvidas pelo UNICEF buscam alcançar os oito Objetivos de Desenvolvimento do Milênio - $\mathrm{ODM}^{\mathrm{ii}}$, entre os quais seis estão relacionados diretamente à infância. A adoção dos ODM reforçou a priorização do financiamento para a educação primária, e tem como meta "Garantir que, até 2015, todas as crianças, de ambos os sexos, terminem um ciclo completo de ensino básico" (ONU, 2000, n.p).

"No ano 2000, o Brasil assumiu os Objetivos do Desenvolvimento do Milênio, comprometendo-se a alcançar até 2015 metas em oito áreas estratégicas para o desenvolvimento humano" (UNICEF, 2014, p. 8). Desde então, segundo o órgão, o país tem avançado em várias áreas:

Entre 1990 e 2012, a taxa de mortalidade entre menores de 5 anos caiu 68,5\% passando de 53,7 mortes para 16,9 por mil nascidos vivos, segundo estimativas do Ministério da Saúde (2012). No mesmo período, a taxa de mortalidade de menores de 1 ano foi reduzida em $68,4 \%$ - de 47,1 mortes para 14,9 por mil nascidos vivos (MS, estimativas em 2012). O acesso ao ensino básico foi ampliado, com 98\% das crianças e adolescentes entre 7 e 14 anos matriculados na escola. Houve redução também nas taxas de trabalho infantil, de 17,9\%, entre 2008 e 2011. Mesmo assim, em 2012, ainda existiam 3,5 milhões de crianças e adolescentes entre 5 e 17 anos no mercado de trabalho, considerando um pouco mais de três milhões de meninos e meninas em situação de trabalho infantil a ser abolido. Outra conquista foi a diminuição da pobreza e da extrema pobreza. De acordo com a definição nacional de pobreza do governo federal (70 reais per capita mensal em julho de 2011), estima-se que esse cenário está mudando. A extrema pobreza caiu de 13,7\% para 3,6\% entre 1992 e 2012, enquanto a pobreza saiu de $31,5 \%$ para $8,5 \%$ (UNICEF, 2014, p. 9).

No que se refere ao objetivo dois, observa-se que "[...] o acesso ao ensino básico foi ampliado, com 98\% das crianças e adolescentes entre 7 e 14 anos matriculados na escola" (UNICEF, 2014, p. 9). 


\section{$e$-Curriculum}

Programa de Pós-Graduação em Educaçãa: Currículo

No tocante aos desafios que ainda precisam ser superados pela educação brasileira, de acordo com o UNICEF (2014), só serão alcançados se o país implementar políticas públicas capazes de reduzir as desigualdades que ainda impedem a sobrevivência e o desenvolvimento de crianças e adolescentes.

Nesse sentido, o UNICEF lança, em 2014, um documento intitulado "Agenda pela Infância 2015-2018: desafios e proposta eleições 2014" (UNICEF, 2014), que apresenta um conjunto de temas para o debate dos candidatos à presidência e governos dos estados com a sociedade civil. Foram propostos sete compromissos a partir da diversidade de necessidades específicas de meninos e meninas que vivem em diversos locais do território brasileiro.

O compromisso dois da agenda visa "Garantir que cada criança e cada adolescente de 4 a 17 anos tenha acesso a escolas públicas inclusivas e de qualidade, aprendendo na idade certa os conhecimentos correspondentes a cada ciclo de vida" (UNICEF, 2014, p. 14).

"Para o UNICEF, é fundamental que o País alcance o objetivo geral e as metas do Plano Nacional de Educação [...]" (UNICEF, 2014, p. 16). No que se refere à educação básica, propõe-se que o executivo federal tenha como objetivo promover juntamente com estados e municípios a inclusão escolar, para que, dessa forma, 100\% das crianças e adolescentes de 04 a 17 anos estejam matriculados nas escolas e aprendam na idade correta. A meta para o executivo estadual é "Fortalecer ações, programas e estratégias, em cooperação com os municípios, para atingir a meta de $100 \%$ das crianças alfabetizadas até os 8 anos de idade, respeitando o multilinguismo das comunidades indígenas" (UNICEF, 2014, p. 17).

No Fórum Mundial de Educação, ocorrido em Dakar (Senegal) no ano 2000, governantes de 164 países com representantes de grupos regionais, organizações internacionais, agências financiadoras, Organizações Não Governamentais e sociedade civil concordaram com o Marco de ação de Dakar: "Educação Para Todos (UNESCO, 2001)".

Destarte, anteriormente, a 'Declaração Mundial de Educação Para Todos' já proclamava como o primeiro de seus objetivos "Satisfazer as necessidades básicas de aprendizagem" e que

Cada pessoa - criança, jovem ou adulto - deve estar em condições de aproveitar as oportunidades educativas voltadas para satisfazer suas necessidades básicas de aprendizagem. Essas necessidades compreendem tanto os instrumentos essenciais para a aprendizagem (como a leitura e a escrita,

Lidiane Malheiros Mariano OLIVEIRA,Lucélia Tavares Guimarães A influência dos organismos multilaterais internacionais na formação das políticas brasileiras de alfabetização. 


\section{e-Curriculum}

a expressão oral, o cálculo, a solução de problemas), quanto os conteúdos básicos da aprendizagem (como conhecimentos, habilidades, valores e atitudes), necessários para que os seres humanos possam sobreviver, desenvolver plenamente suas potencialidades, viver e trabalhar com dignidade, participar plenamente do desenvolvimento, melhorar a qualidade de vida, tomar decisões fundamentadas e continuar aprendendo. A amplitude das necessidades básicas de aprendizagem e a maneira de satisfazê-las variam segundo cada país e cada cultura, e, inevitavelmente, mudam com o decorrer do tempo (UNESCO, 1990, p. 3, grifos no original).

Nesse aspecto, vale destacar que a educação básica é considerada o alicerce para outras formas de aprendizagem e desenvolvimento humano, e para tal, faz-se necessário um forte comprometimento político nacional e internacional com a Educação Para Todos - EPT, e o aumento de investimentos significativos no ensino fundamental.

A proposta era ter alcançado seis importantes objetivos educacionais e suas respectivas metas até 2015. Como forma de acompanhar o progresso e identificar as lacunas dessas ações, a UNESCO iniciou os Relatórios de Monitoramento de EPT para agenda global de desenvolvimento sustentável pós-2015.

O tema alfabetização aparece no objetivo seis do EPT:

Objetivo 6 - Qualidade da Educação. Melhorar todos os aspectos da qualidade da educação e garantir excelência para que resultados de aprendizagem mensuráveis e reconhecidos sejam alcançados por todos, principalmente em alfabetização, conhecimentos básicos em matemática (numeracy) e habilidades essenciais para a vida (UNESCO, 2015, p. 8).

"A questão da alfabetização se manifesta em todos os objetivos da EPT porque é uma ferramenta de aprendizagem e um dos resultados principais da educação" (RICHMOND; ROBINSON; SACHS-ISRAEL, 2009, p. 12).

Como mais uma estratégia para chamar atenção para a alfabetização e estimular atividades na área, a UNESCO estabeleceu a Década das Nações Unidas para a Alfabetização UNLD (UNESCO, 2005), a fim de propor uma nova visão de alfabetização no contexto da Educação Para Todos, e criou um conjunto de metas e ações, de abrangência internacional. Assim, a 'Década' priorizou suas ações para jovens e adultos analfabetos, principalmente 


\section{e-Curriculum}

Programa de Pós-Graduação em Educação: Currículo

mulheres, crianças e jovens ainda não matriculados nas escolas, sobretudo meninas e crianças na escola, porém sem acesso à educação de qualidade, para que não se tornem adultos analfabetos.

Durante essa "Década", vêm sendo implementadas, no Brasil, várias iniciativas baseadas no monitoramento dessas ações. Mortatti (2013), ao fazer um balanço crítico da UNLD, observa a conquista de alguns avanços se considerados os princípios e metas estabelecidos em consonância com os definidos por organismos multilaterais. No entanto, identificou o agravamento de muitos problemas históricos, entre os quais destaca:

[...] o silenciamento da discussão em torno do conceito restrito e rudimentar de alfabetização, no qual, em consonância com o princípio do "aprender a aprender" derivado de modelo político neoliberal, fundamentam-se as políticas educacionais e correspondentes "sistemas de avaliação" de habilidades e competências de leitura e escrita, a partir das quais se espera que os alunos aprendam e são definidoras da função do professor como mero "provedor de estratégias" para essa aprendizagem (MORTATTI, 2013, p. 16-17).

De acordo com a autora, as avaliações em larga escala são usadas como um dos instrumentos para monitorar a efetividade dessas políticas. Avaliam-se os resultados em função dos objetivos que se buscam alcançar. O procedimento do professor em sala de aula deve garantir estratégias que levem seus alunos a "aprender a aprender", melhorem os resultados nas avaliações externas e, dessa forma, contribuam para que o país alcance as metas globais de alfabetização. Nesse sentido, conforme Mortatti (2013, p. 27), não caberia perguntar "[...] o que, por que, para que ensinar a ler e a escrever, ou quem é o responsável por esse ensino e qual a especificidade de seu ofício?"

A autora chama a atenção para a necessidade de problematizar a consensual meta da qualidade de educação e de alfabetização escolar de crianças defendida por essas organizações internacionais e pelas políticas públicas brasileiras, uma vez que o processo de alfabetização das crianças que frequentam a escola e têm experiência de frustração quando não conseguem aprender a ler e escrever tem sido abordado somente quando é traduzido em dados quantificáveis, nas avaliações nacionais. Dessa forma, os problemas de alfabetização no Brasil são explicados como:

Lidiane Malheiros Mariano OLIVEIRA,Lucélia Tavares Guimarães A influência dos organismos multilaterais internacionais na formação das políticas brasileiras de alfabetização. 


\section{e-Curriculum}

[...] resultantes de dificuldades do aluno em aprender, ou do professor em ensinar, ou de insuficiente envolvimento das famílias na vida escolar das crianças, ou de ineficiente atuação dos gestores da educação, ou de aplicação inadequada de investimentos financeiros. Em outras palavras, vêm-se discutindo e propondo soluções somente para problemas que, em âmbito sistêmico, conseguem se formular como tais e cuja formulação já contém as possibilidades de respostas disponíveis (MORTATTI, 2013, p. 25).

Com todos os olhares voltados a essas questões, os conceitos de alfabetização trabalhados nas salas de alfabetização brasileiras acabam por se tornarem inquestionáveis, e isso, no ponto de vista da autora, mostra que tem se estabelecido no Brasil uma "tradição" com modelos de ensino a partir dos métodos de alfabetização. Na década de 1980, o modelo foi o Construtivismo; na década de1990, de forma mais eclética, vieram a se juntar propostas de letramento ou propostas de métodos fônicos. No entanto, a pergunta central, no que se refere a questões didáticas na sala de aula, continua sendo

[...] como o professor deve proceder para garantir que seus alunos "aprendam a aprender", visando à obtenção de melhores resultados nas avaliações internas e externas à escola, contribuindo para que o país alcance as metas globais para a educação e a alfabetização, em particular a meta de todas as crianças alfabetizadas até os 8 anos de idade? Mas, nessa "nova tradição", não cabe perguntar: o que, por que, para que ensinar a ler e a escrever, ou quem é o responsável por esse ensino e qual a especificidade de seu ofício? (MORTATTI, 2013, p. 27, grifo da autora).

Ou seja, embora a alfabetização seja considerada um direito do cidadão e existam investimentos do Estado brasileiro em políticas públicas que focam esse problema, o principal objetivo da alfabetização no Brasil continua sendo atingir as metas propostas por organismos multilaterais. Assim, questões que tratam das especificidades do processo de alfabetização não aparecem nas propostas e relatórios desses organismos.

De acordo com a UNESCO, os relatórios de 'Monitoramento Global de Educação para Todos' apresentados até 2015 tiveram papel importante para apoiar os países, oferecer avaliações e análises concretas para sustentar o desenvolvimento de novas políticas, assim como apresentar uma poderosa ferramenta de defesa e promoção para os governos e a sociedade civil. 


\section{$e$-Curriculum}

Programa de Pós-Graduação em Educação: Currículo

O relatório da EPT de 2015 reconhece que, desde 2000, houve muitos progressos, mas ainda há muito a se fazer. "O lado positivo é que o número de crianças e adolescentes fora da escola diminuiu quase pela metade desde 2000. Estima-se que 34 milhões de crianças a mais terão frequentado a escola em decorrência do progresso mais rápido desde Dakar" (UNESCO, 2015, p. 3). No entanto, segundo o documento, 58 milhões de crianças no mundo ainda estão fora da escola e estima-se que cerca de 100 milhões não concluirão a educação primária. Além disso, outros milhões deixam a escola sem terem aprendido o básico em razão da baixa qualidade da aprendizagem no nível primário.

"As crianças mais pobres do mundo têm chances quatro vezes maiores de não frequentar a escola quando comparadas às crianças mais ricas do mundo, e cinco vezes maiores de não completar a educação primária" (UNESCO, 2015, p. 3).

Segundo o documento da UNESCO, os avanços obtidos se deram em relação ao acesso à escola; no entanto, a questão da qualidade da educação que essas crianças receberam ao frequentar a escola não foi suficiente para apreender o necessário. Dessa forma, provavelmente, a ênfase para que a aprendizagem e a qualidade se tornem temas centrais no marco global pós-2015 será maior, “[...] uma vez que, conforme apontou o RMG 2013/14, 250 milhões de crianças não tiveram a oportunidade de aprender o básico - embora 130 milhões delas tenham frequentado a escola por pelo menos quatro anos" (UNESCO, 2015, p. 41).

De acordo com Cury (2002, p. 246),

Hoje, praticamente, não há país no mundo que não garanta, em seus textos legais, o acesso de seus cidadãos à educação básica. Afinal, a educação escolar é uma dimensão fundante da cidadania, e tal princípio é indispensável para políticas que visam à participação de todos nos espaços sociais e políticos e, mesmo, para reinserção no mundo profissional (CURY, 2002, p. 246).

O autor supracitado afirma que são inegáveis os esforços da UNESCO no sentido da universalização do ensino fundamental para todos, já que "É inegável também a dificuldade de, diante da desigualdade social, instaurar um regime em que a igualdade política aconteça no sentido de diminuir as discriminações" (CURY, 2002, p. 247).

Os objetivos da EPT e os objetivos de desenvolvimento do milênio em educação destacam a necessidade de se expandir a educação primária gratuita e de boa qualidade, o que 


\section{e-Curriculum}

Programa de Pós-Graduação em Educação: Currículo

exige maiores investimentos dos orçamentos educacionais. "Apesar disso, dos 56 países com dados disponíveis sobre a parcela dos investimentos públicos domésticos na educação primária, tanto em 1999 quanto em 2012, apenas 16 aumentaram essa porcentagem” (UNESCO, 2015, p. 48).

A educação é a chave para se alcançar a maioria dos objetivos da agenda de desenvolvimento pós-2015, desde o consumo sustentável até sociedades saudáveis e pacíficas. Os programas e as abordagens educacionais deveriam ser reelaborados para alcançar esses objetivos (UNESCO, 2015, p. 54).

Observa-se, nos referidos documentos analisados do Banco Mundial, UNESCO e UNICEF, uma preocupação com a qualidade da educação no Brasil, o que na visão neoliberal anuncia

[...] a incapacidade estrutural do Estado para administrar as políticas sociais. Esse fato, sendo um atributo geral do assistencialismo estatal, expressa-se como uma peculiaridade própria do campo educacional: a crise de produtividade da escola não sintetiza outra coisa senão a crise do centralismo e da burocratização próprias de todo Estado interventor (GENTILI, 1998, p. 17).

Nesse sentido, segundo a perspectiva neoliberal, os governos foram incapazes de assegurar o acesso da grande massa de alunos às escolas e ao mesmo tempo garantir a eficiência produtiva que deve caracterizar a prática pedagógica das instituições escolares.

Os relatórios de monitoramento das políticas brasileiras instituídos por essas organizações multilaterais apontam uma melhora no acesso e na permanência dos estudantes na educação básica; no entanto, a questão da qualidade ainda não está de acordo com os padrões esperados.

Apesar de haver vários documentos de caráter internacional assinados por países das Nações Unidas e também por empresas ou representantes do "terceiro setor iii , que reconhecem ou garantem o acesso à educação básica a todos os cidadãos, como é o caso dos Objetivos de Desenvolvimento do Milênio, Educação Para Todos, Compromisso Todos pela Educação, o 


\section{e-Curriculum}

Programa de Pós-Graduação em Educaçãa: Currículo

direito à educação escolar deve ser garantido inicialmente nas leis nacionais, como aponta Cury (2002, p. 246):

[...] a primeira garantia é que ele esteja inscrito em lei de caráter nacional. O contorno legal indica os direitos, os deveres, as proibições, as possibilidades e os limites de atuação, enfim: regras. Tudo isso possui enorme impacto no cotidiano das pessoas, mesmo que nem sempre elas estejam conscientes de todas as suas implicações e consequências (CURY, 2002, p. 246).

Mesmo que as regras estabelecidas por essas leis entrem em choque com as diferentes realidades sociais e econômicas de funcionamento da sociedade, configuram-se como obrigação do Estado. No próximo tópico, abordamos as mais recentes políticas elaboradas no Brasil, em consonância com os documentos dos órgãos multilaterais mencionados anteriormente.

\section{O PLANO NACIONAL DE EDUCAÇÃO E O 'COMPROMISSO TODOS PELA EDUCAÇÃO'}

O documento intitulado Compromisso Todos pela Educação foi criado em 2006, na Conferência Ações de Responsabilidade Social em Educação: melhores práticas da América Latina, por personalidades e representantes de empresas brasileiras para propor compromissos com vistas à melhoria da educação. O movimento ganhou adesão de diversas organizações da sociedade civil: pais, profissionais da mídia, intelectuais, empresários, sindicalistas, estudantes e também do governo federal.

Dessa forma, o Decreto $\mathrm{n}^{\circ}$ 6.094, de 24 de abril de 2007 (BRASIL, 2007), determina a implementação do 'Plano de Meta Compromisso Todos pela Educação', pela União Federal, em regime de colaboração com os estados, municípios e distrito federal, assim como a família e a comunidade, mediante programas e ações de assistência técnica e financeira, com o objetivo de mobilizar a sociedade pela melhoria da qualidade da educação básica.

Como está descrito no artigo $2^{\circ}$ da referida lei, a participação da União no Compromisso foi pautada pela realização direta ou pelo incentivo e apoio à implementação, por municípios, Distrito Federal, estados e respectivos sistemas de ensino, de acordo com vinte e oito diretrizes.

Lidiane Malheiros Mariano OLIVEIRA,Lucélia Tavares Guimarães A influência dos organismos multilaterais internacionais na formação das políticas brasileiras de alfabetização. 


\section{e-Curriculum}

Programa de Pós-Graduação em Educação: Currículo

No que se refere à alfabetização, o inciso segundo estabelece que se deve "[...] alfabetizar as crianças até, no máximo, os oito anos de idade, aferindo os resultados por exame periódico específico" (BRASIL, 2007, n.p), o que demonstra a adequação em relação à idade ideal para alfabetizar as crianças apresentada pelo PNAIC.

A qualidade da educação será avaliada periodicamente e o "O IDEB será o indicador objetivo para a verificação do cumprimento de metas fixadas no termo de adesão ao Compromisso" (BRASIL, 2007, n.p).

O Compromisso Todos pela Educação visa mobilizar a iniciativa privada e organizações sociais do chamado "terceiro setor" para atuar de forma convergente, complementar e sinérgica com o Estado no provimento das políticas públicas. O ponto central de sua estratégia é a corresponsabilidade e a busca da eficiência, eficácia, e efetividade. Seu enfoque primordialmente voltado à melhoria da qualidade do ensino traduzida em indicadores mensuráveis obtidos por meio das avaliações externas (SHIROMA; GARCIA; CAMPOS, 2011, p. 233).

Ainda de acordo com os autores supracitados, todos os sujeitos intrincados nesse processo são sensibilizados a serem protagonistas participativos e ativos, como forma de criar uma nova consciência social de responsabilidade e apostar na educação como instrumento de produção de mudanças na sociedade. Nesse sentido, "[...] sob forte influência das orientações e condicionalidades derivadas de acordos brasileiros com os organismos multilaterais, gestou-se a reforma educacional brasileira no bojo da reforma do estado" (SHIROMA; GARCIA; CAMPOS, 2011, p. 227). A reforma brasileira também se apoiou na ideia de um sistema educacional baseado na tríade "eficiência, eficácia e efetividade".

A resolução da crise educacional implicava, entre outros aspectos, a descentralização das atividades para as unidades escolares, a introdução de mecanismos de avaliação dos resultados e a responsabilização de todos "os atores sociais" pela efetivação das mudanças necessárias (SHIROMA; GARCIA; CAMPOS, 2011, p. 227). 


\section{$e$-Curriculum}

Programa de Pós-Graduação em Educaçãa: Currículo

Portanto, tal processo demandava um grande pacto, que vai além de investimentos financeiros do Estado, pois envolve todos os setores sociais. "Seu enfoque é primordialmente voltado à melhoria da qualidade do ensino traduzida em indicadores mensuráveis obtidos por meio de avaliações externas" (SHIROMA; GARCIA; CAMPOS, 2011, p. 233) e, dessa forma, possibilita que a sociedade monitore a evolução desses indicadores e exija de si mesma e do governo uma melhoria. As autoras supracitadas apontam nesse movimento a intencionalidade de "educar" a sociedade, sobretudo no que se refere aos pais, convocados a exercer o controle e a fiscalização sobre as ações da escola e do estado. A adesão do MEC ao movimento se anuncia na inclusão de suas metas no Plano de Desenvolvimento da Educação - PDE.

Saviani (2007, p. 1253) afirma que o Compromisso Todos pela Educação pode ser traduzido por uma pedagogia de resultados, uma vez que "[...] o governo se equipa com instrumentos de avaliação dos produtos, forçando, com isso, que o processo se ajuste às exigências postas pela demanda das empresas". Assim, com a educação guiada por uma lógica de mercado, considerada um produto produzido com qualidade mutável, os professores passam a ser considerados prestadores de serviços e os alunos, seus clientes. "No entanto, de fato, sob a égide da qualidade total, o verdadeiro cliente das escolas é a empresa ou a sociedade e os alunos são produtos que os estabelecimentos de ensino fornecem a seus clientes" (SAVIANI, 2007, p. 1253). Para o autor, a satisfação dos "clientes" é o que de fato os empresários fiadores do Compromisso Todos pela Educação almejam do plano de Desenvolvimento de Educação lançado pelo MEC.

O PDE foi lançado em 24 de abril de 2007, anunciado após o Decreto $\mathrm{n}^{\circ} 6.094$, que dispõe sobre o "Plano de metas Compromisso Todos pela Educação", com ações que abrangem todos os níveis e modalidades de ensino, infraestrutura e medidas de apoio, com destaque para as que tratam da educação básica e foram agrupadas no "Programa de Metas Compromisso Todos pela Educação" (BRASIL, 2007).

A concepção de educação que inspira o Plano de Desenvolvimento da Educação (PDE), no âmbito do Ministério da Educação, e que perpassa a execução de todos os seus programas reconhece na educação uma face do processo dialético que se estabelece entre socialização e individuação da pessoa, que tem como

Lidiane Malheiros Mariano OLIVEIRA,Lucélia Tavares Guimarães A influência dos organismos multilaterais internacionais na formação das políticas brasileiras de alfabetização. 


\section{$e$-Curriculum}

Programa de Pós-Graduação em Educação: Currículo

objetivo a construção da autonomia, isto é, a formação de indivíduos capazes de assumir uma postura crítica e criativa frente ao mundo (HADDAD, 2008, p. 5).

De acordo com Saviani (2007), o PDE teve recepção favorável pela opinião pública, uma vez que seria um plano que finalmente estaria disposto a enfrentar a questão da qualidade de ensino ministrado em todas as escolas de educação básica do país.

Confrontando-se a estrutura do Plano Nacional de Educação (PNE) com a do Plano de Desenvolvimento da Educação (PDE), constata-se que o segundo não constitui um plano, em sentido próprio. Ele se define, antes, como um conjunto de ações que, teoricamente, se constituiriam em estratégias para a realização dos objetivos e metas previstos no PNE (SAVIANI, 2007, p. 1239).

Ou seja, um plano de ações a ser executado, um conjunto de programas que visam atingir as metas estabelecidas no Plano Nacional de Educação (2001); no entanto, usa-se o termo “teoricamente", porque o PDE não se define como uma estratégia para o cumprimento das metas do PNE. O PDE "[...] não parte do diagnóstico, das diretrizes e dos objetivos e metas constitutivos do PNE, mas se compõe de ações que não se articulam organicamente com este" (SAVIANI, 2007, p. 1239). O autor cita como exemplo, no caso do ensino fundamental, que a Provinha Brasil, instituída pelo PDE, não estava prevista no PNE. Da mesma forma, o Programa Dinheiro Direto na escola, que consiste em um programa de racionalização de gestão, também não está relacionado diretamente com as metas, apesar de incidir sobre a "eficácia e efíciência da escola" e, desse modo, apresentar metas a serem alcançadas.

"Apenas a meta 17 do PNE encontra-se diretamente contemplada no PDE, por meio da ação 'Transporte Escolar'. As demais 29 metas fixadas pelo PNE para o ensino fundamental não são objeto de consideração por parte de PDE" (SAVIANI, 2007, p. 1240). O autor conclui que o PDE foi formulado sem considerar o que está disposto no PNE e foi, gradativamente, colocado como um novo plano para substituí-lo, embora não tenha sido aprovada uma lei que revogasse o plano em vigor desde 2001.

A Lei $n^{\circ}$ 13.005, de 25 de junho de 2014 (BRASIL, 2014a), aprova o novo Plano Nacional de Educação, com vigência para dez anos após a data da publicação. O PNE é um 


\section{e-Curriculum}

Programa de Pós-Graduação em Educação: Currículo

instrumento brasileiro de planejamento do Estado democrático de direito, que orienta a execução e o aprimoramento de políticas públicas do setor.

Entre as dez diretrizes do PNE explícitas no artigo $2^{\circ}$, o inciso primeiro aborda “[...] a erradicação do analfabetismo" (BRASIL, 2014a, n.p). Cabe salientar que o cumprimento do PNE e de suas metas é monitorado continuamente, por meio de avaliação realizada pelas seguintes instâncias: MEC; Comissão de Educação da Câmara dos Deputados e Comissão de Educação, Cultura e Esporte do Senado Federal; Conselho Nacional de Educação; e Fórum Nacional de Educação. Compete também a essas instâncias a responsabilidade de divulgar os resultados do monitoramento e das avaliações nos respectivos sítios institucionais na internet, analisar e propor políticas públicas para assegurar a implementação das estratégias e o cumprimento das metas, assim como avaliar e sugerir a revisão do percentual de investimento público na educação.

Entre as vinte metas do PNE, a meta cinco tem como objetivo "[...] alfabetizar todas as crianças, no máximo, até o final do $3^{\circ}$ (terceiro) ano do ensino fundamental" (BRASIL, 2014a, n.p). O analfabetismo funcional, cuja raiz é encontrada nas séries iniciais do ensino fundamental, mostra os problemas presentes nos processos de escolarização. "Dados do Censo Demográfico de 2010 revelaram que $15,2 \%$ das crianças brasileiras com 8 anos de idade que estavam cursando o ensino fundamental eram analfabetas" (BRASIL, 2014b, p. 26).

As estratégias propostas para a erradicação do analfabetismo encontram-se na meta cinco, a saber:

Estruturar os processos pedagógicos de alfabetização, nos anos iniciais do ensino fundamental, articulando-os com as estratégias desenvolvidas na préescola, com qualificação e valorização dos(as) professores(as) alfabetizadores(as) e com apoio pedagógico específico, a fim de garantir a alfabetização plena de todas as crianças; instituir instrumentos de avaliação nacional periódicos e específicos para aferir a alfabetização das crianças, aplicados a cada ano, bem como estimular os sistemas de ensino e as escolas a criarem os respectivos instrumentos de avaliação e monitoramento, implementando medidas pedagógicas para alfabetizar todos os alunos e alunas até o final do terceiro ano do ensino fundamental; selecionar, certificar e divulgar tecnologias educacionais para a alfabetização de crianças, assegurada a diversidade de métodos e propostas pedagógicas, bem como o acompanhamento dos resultados nos sistemas de ensino em que forem aplicadas, devendo ser disponibilizadas, preferencialmente, como recursos educacionais abertos; fomentar o desenvolvimento de tecnologias educacionais e de práticas 


\section{e-Curriculum}

pedagógicas inovadoras que assegurem a alfabetização e favoreçam a melhoria do fluxo escolar e a aprendizagem dos(as) alunos(as), consideradas as diversas abordagens metodológicas e sua efetividade; apoiar a alfabetização de crianças do campo, indígenas, quilombolas e de populações itinerantes, com a produção de materiais didáticos específicos, e desenvolver instrumentos de acompanhamento que considerem o uso da língua materna pelas comunidades indígenas e a identidade cultural das comunidades quilombolas; promover e estimular a formação inicial e continuada de professores(as) para a alfabetização de crianças, com o conhecimento de novas tecnologias educacionais e práticas pedagógicas inovadoras, estimulando a articulação entre programas de pósgraduação stricto sensu e ações de formação continuada de professores(as) para a alfabetização; apoiar a alfabetização das pessoas com deficiência, considerando as suas especificidades, inclusive a alfabetização bilíngue de pessoas surdas, sem estabelecimento de terminalidade temporal (BRASIL, 2014a, n.p).

Muitas e importantes estratégias têm sido propostas no contexto do atual Plano Nacional de Educação para orientar a implantação de políticas, com o intuito de erradicar o analfabetismo no Brasil. No entanto, não basta que as redes de ensino façam adesão a essas políticas; será necessário que o Estado forneça estrutura para a implementação desses programas e, ainda, que todos os envolvidos - estado, sociedade, família e profissionais da educação - estejam empenhados em elevar a taxa de alfabetismo nas escolas.

Mortatti (2013) explica que predomina uma repetição nas discussões e propostas de intervenção das políticas públicas em relação aos princípios políticos subjacentes às metas que os organismos multilaterais estabelecem. O Plano de Metas Compromisso Todos pela Educação (BRASIL, 2007), assim como o recente Plano Nacional de Educação (BRASIL, 2014a), trazem metas similares aos compromissos e metas estabelecidos pelos organismos multilaterais, pautados na crescente participação da sociedade e em parcerias com o setor privado.

Especificamente em relação à alfabetização, tanto a UNESCO como o UNICEF propõem que as crianças sejam alfabetizadas na "idade certa", ou seja, até os oito anos de idade, o que deve ser aferido por exames periódicos. Dessa forma, a meta cinco do PNE reafirma o objetivo de "[...] alfabetizar todas as crianças, no máximo, até o final do $3^{\circ}$ (terceiro) ano do ensino fundamental" (BRASIL, 2014a, n.p) - objetivo presente também nos outros documentos analisados. 


\section{e-Curriculum}

Programa de Pós-Graduação em Educação: Currículo

Para Saviani, o "fracasso" dessas campanhas de alfabetização explica-se pelo fato de que o processo de alfabetização se dá por encerrado após a conclusão do primeiro e segundo ano, por se considerar que o objetivo da alfabetização já teria sido alcançado e, dessa forma, pela falta de continuidade no processo, em pouco tempo as crianças voltam à condição de analfabetas.

Fracassam porque elas são esporádicas, elas são descontínuas, não duram o tempo suficiente para se atingir o ponto de irreversibilidade. Em geral, os alfabetizandos, após alguns meses, chegam a redigir bilhetes simples, chegam a escrever pequenos textos e aí se comemora o feito de que em poucos meses se alfabetizou, dá-se o diploma, faz-se uma festa e depois de um ano os diplomados regridem à condição de analfabetos. Em verdade, a forma própria de se resolver esse problema é a universalização da escola elementar. Não surgiu ainda um mecanismo mais adequado (SAVIANI, 2007, p. 1247).

Assim, de acordo com o autor, o processo de alfabetização deve continuar até a quarta ou quinta "série"iv do ensino fundamental, com maior empenho para garantir o domínio da estrutura formal da língua nos dois primeiros anos, sem que o processo de alfabetização seja segmentado, o que traz prejuízo às crianças em processo de aprendizagem, sem considerá-la um processo irreversível.

\section{CONSIDERAÇÕES FINAIS}

Observamos nos referidos documentos analisados do Banco Mundial, UNESCO e UNICEF uma preocupação com a qualidade da educação no Brasil. Os relatórios de monitoramento das políticas brasileiras instituídos por essas organizações multilaterais apontam uma melhora no acesso e na permanência dos estudantes na educação básica; no entanto, a questão da qualidade ainda não está de acordo com os padrões esperados.

Mortatti (2013) explica que predomina uma repetição nas discussões e propostas de intervenção nas políticas públicas dos princípios políticos subjacentes às metas que os organismos multilaterais estabelecem.

Especificamente em relação a alfabetização, tanto a UNESCO como o UNICEF propõem que as crianças sejam alfabetizadas na "idade certa", ou seja, até os oito anos de idade e 


\section{e-Curriculum}

Programa de Pós-Graduação em Educação: Currículo

seja realizada aferição periódica dos resultados. Dessa forma, a meta cinco do PNE tem como objetivo "alfabetizar todas as crianças, no máximo, até o final do $3^{\circ}$ (terceiro) ano do ensino fundamental", assim como previsto também nos outros documentos analisados.

Após realização de estudos de documentos elaborados pela UNESCO, UNICEF e Banco Mundial a partir da conferência mundial de "Educação para todos", em 1990, foi possível verificar muita similaridade entre os aspectos priorizados nas recomendações de organismos multilaterais e as políticas implantadas no Brasil.

O PDE (2007), o Plano de Metas Compromisso Todos pela Educação (Decreto $\mathrm{n}^{\circ}$ 6094/2007), assim como o recente Plano Nacional de Educação (Lei n 13.005/2014a) estabelecem em suas metas uma similaridade com os compromissos e metas estabelecidos pelos organismos multilaterais. É possível perceber uma crescente participação da sociedade e o estabelecimento de uma parceria com o setor privado, com o objetivo de criar estratégias para se atingir esses propósitos, assim como reforçar a ideia de um sistema educacional baseado na tríade eficiência, eficácia e efetividade. 


\section{e-Curriculum}

\section{REFERÊNCIAS}

AFONSO, Almerindo Janela. Reforma do estado e políticas educacionais: entre a crise do estadonação e a emergência da regulação supranacional. Educação \& Sociedade, Braga, Portugal, ano XXII, n. 75, p. 13-32, ago. 2001.

AFONSO, Carla Winter; GUBERMAN, Garson. Influência dos organismos internacionais na política nacional de ensino brasileira. In: ENCONTRO DE ESTUDOS EM ESTRATÉGIA, III., 2007, São Paulo. Anais... São Paulo: RAE Publicações, 2007.

ALTMANN, Helena. Influências do Banco Mundial no projeto educacional brasileiro. Educação e Pesquisa, São Paulo, v. 28, n. 1, p. 77-89, jan./jun. 2002.

BANCO MUNDIAL. Relatório nº 63731-BR - Estratégia de parceria de país para a República Federativa do Brasil: exercícios fiscais 2012 a 2015. Washington, D.C., 21 set. 2011. Disponível em:

<http://siteresources.worldbank.org/BRAZILINPOREXTN/Resources/BRCPSPortugues.pdf?res ourceurlname=BRCPSPortugues.pdf $>$. Acesso em: 15 ago. 2015.

BRASIL. Lei no 13.005, de 25 de junho de 2014. Aprova o Plano Nacional de Educação - PNE e dá outras providências. Diário Oficial da União, Brasília, 2014a.

. Ministério da Educação. Secretaria de Articulação com os Sistemas de Ensino.

Planejando a próxima década conhecendo as 20 metas do Plano Nacional de Educação. Brasília, DF: MEC/SASE, 2014b.

Decreto $n^{\circ}$ 6.094, de 24 de abril de 2007. Dispõe sobre a implementação do Plano de Metas Compromisso Todos pela Educação, pela União Federal, em regime de colaboração com municípios, Distrito Federal e Estados, e a participação das famílias e da comunidade. Diário Oficial da União, Brasília, 2007.

. Lei n ${ }^{\circ} 10.172$, de 9 de janeiro de 2001. Aprova o Plano Nacional de Educação e dá outras providências. Diário Oficial da União, Brasília, 2001.

CURY, Carlos Roberto Jamil. Direito à educação: direito à igualdade, direito à diferença. Cadernos de pesquisa, São Paulo, n. 116, p. 245-262, 2002.

DELORS, Jacques et al. Educação: um tesouro a descobrir. Relatório para a UNESCO da Comissão Internacional sobre Educação para o século XXI. São Paulo: UNESCO, 1996.

Lidiane Malheiros Mariano OLIVEIRA,Lucélia Tavares Guimarães A influência dos organismos multilaterais internacionais na formação das políticas brasileiras de alfabetização. 


\section{e-Curriculum}

Programa de Pós-Graduação em Educação: Currículo

DELORS, Jacques et al. Educação: um tesouro a descobrir. Relatório para a UNESCO da Comissão Internacional sobre Educação para o século XXI. 10. Ed. São Paulo: Cortez; Brasília: UNESCO, 2006.

GENTILI, Pablo. A falsificação do consenso: simulacro e imposição na reforma educacional do neoliberalismo. Petrópolis: Vozes, 1998.

HADDAD. Fernando. O Plano de Desenvolvimento da Educação: razões, princípios e programas. Brasília: Instituto Nacional de Estudos e Pesquisas Educacionais Anísio Teixeira, 2008.

MONTAÑO, Carlos. O terceiro setor e a questão social. São Paulo: Cortez, 2002.

MORTATTI, Maria do Rosário Longo. Um balanço crítico da "década da alfabetização" no Brasil. Cadernos Cedes, Campinas, v. 33, n. 89, p. 15-34, 2013.

ONU. Objetivos de desenvolvimento do milênio até 2015. 2000. (Reunião: Cúpula do Milênio da ONU). Diponível em: <http://www.unicef.org/brazil/pt/resources_9540.htm>. Acesso em: 18 jul. 2015.

PIANA, Maria Cristina. A construção do perfil do assistente social no cenário educacional. São Paulo: Editora UNESP/Cultura Acadêmica, 2009.

RICHMOND, Mark; ROBINSON, Clinton; SACHS-ISRAEL, Margarete. O desafio da alfabetização global: um perfil da alfabetização de jovens e adultos na metade da Década das Nações Unidas para a Alfabetização 2003-2012. Paris, França: Unesco, 2009.

SAVIANI, Dermeval. O Plano de Desenvolvimento da Educação: análise do projeto do MEC. Educação e Sociedade, Campinas, v. 28, n. 100, p. 1231-1255, 2007.

SHIROMA, Eneida Oto; GARCIA, Rosalba Maria Cardoso; CAMPOS, Roselane Fátima. Conversão das "almas" pela liturgia da palavra: uma análise do discurso do movimento Todos pela Educação. In: BALL, Stephen J.; MAINARDES, Jefferson (Orgs.). Políticas Educacionais: questões e dilemas. São Paulo: Cortez, 2011. p. 222-247.

SHIROMA, Eneida Oto; MORAES, Maria Célia Marcondes de; EVANGELISTA, Olinda. Política educacional. 4.ed. Rio de Janeiro: Lamparina, 2011.

UNESCO. Relatório de Monitoramento Global de EPT 2015. Relatório Conciso Educação para todos 2000-2015: progressos e desafios. Trad. Marina Mendes. Paris: UNESCO, 2015. 


\section{e-Curriculum}

Programa de Pós-Graduação em Educação: Currículo

. Década da Educação das Nações Unidas para um Desenvolvimento Sustentável, 2005-2014: documento final do esquema internacional de implementação. Trad. Regina Coeli Machado. Brasília: UNESCO, 2005.

. Educação para todos: o compromisso de Dakar. Brasília: UNESCO/CONSED, 2001.

. Declaração Mundial sobre Educação para Todos: satisfação das necessidades básicas de aprendizagem. Jontiem, Tailândia, 1990. (Conferência Mundial sobre Educação para Todos).

UNICEF. Agenda para infância 2015-2018: desafios e propostas eleições 2014. Brasília: UNICEF, 2014.

. Declaração Mundial sobre Educação para Todos: plano de ação para satisfazer as necessidades básicas de aprendizagem. Jomtiem: Unicef, 1990. Disponível em: <http://www.direitoshumanos.usp.br/index.php/Direito-a-Educa\%C3\%A7\%C3\%A3o/declaracaomundial-sobre-educacao-para-todos.html>. Acesso em 18 abr. 2016.

Notas

' Para mais informações sobre as estratégias e projetos que o Banco Mundial desenvolve no Brasil acessar o link: <http://www.worldbank.org/pt/country/brazil/overview\#2>.

ii As metas do milênio foram estabelecidas pela ONU em 2000, com o apoio de 191 nações, e ficaram conhecidas como Objetivos de Desenvolvimento do Milênio (ODM). São eles: Acabar com a fome e a miséria; oferecer educação básica de qualidade para todos; promover a igualdade entre os sexos e a autonomia das mulheres; reduzir a mortalidade infantil; melhorar a saúde das gestantes; combater a Aids, a malária e outras doenças; garantir qualidade de vida e respeito ao meio ambiente e estabelecer parcerias para o desenvolvimento. Mais informações acessar o link: <http://www.unicef.org/brazil/pt/resources_9540.htm>.

iii O Terceiro Setor envolve instituições privadas atuando com funções públicas. Para mais informações sobre o tema consultar o texto de Montaño (2002).

iv O autor utiliza o termo "série", visto que na data em que o artigo foi escrito o ensino fundamental ainda estava organizado por "séries" e não por "anos escolares", como está organizado atualmente.

Artigo recebido em 04/12/2016. Aceito para publicação em 31/07/2017. 